\title{
Quality assurance of solar UV irradiance in the Arctic $\dagger$
}

\author{
Julian Gröbner, ${ }^{* a}$ Gregor Hülsen, ${ }^{a}$ Sigrid Wuttke, ${ }^{b}$ Otto Schrems, ${ }^{c}$ Sara De Simone, ${ }^{d}$ Veronica Gallo, ${ }^{d}$ \\ Claudio Rafanelli, ${ }^{d}$ Boyan Petkov, ${ }^{e}$ Vito Vitale, ${ }^{e}$ Kåre Edvardsen ${ }^{f}$ and Kerstin Stebel ${ }^{f}$
}

\author{
Received 18th November 2009, Accepted 19th January 2010 \\ First published as an Advance Article on the web 11th February 2010 \\ DOI: $10.1039 / \mathrm{b} 9 \mathrm{pp} 00170 \mathrm{k}$
}

\begin{abstract}
The first Arctic intercomparison of three solar ultraviolet (UV) spectroradiometers and two multifilter radiometers was held in May and June 2009 at Ny-Ålesund, Svalbard, Norway. The transportable reference spectroradiometer QASUME acted as reference instrument for this intercomparison. The measurement period extended over eleven days, comprising clear sky and overcast weather conditions. Due to the high latitude, measurements could be performed throughout the day during this period. The intercomparison demonstrated that the solar UV measurements from all instruments agreed to within $\pm 15 \%$ during the whole measurement period, while the spectroradiometer from the Alfred-Wegener Institute agreed to better than $\pm 5 \%$. This intercomparison has demonstrated that solar UV measurements can be performed reliably in the high-latitude Arctic environment with uncertainties comparable to mid-latitude sites.
\end{abstract}

\section{Introduction}

Even though UV radiation represents only a small fraction (less than about $8 \%$ ) of the total energy coming from the Sun it has a very important influence on our planet, the chemistry of the atmosphere on the one hand and its influence on the biosphere on the other. The Arctic is considered to be a crucial region with regard to its impact on Earth's climate. ${ }^{1}$ Furthermore it is a region which is mainly indirectly affected by human activities, thus making it an attractive place for studying background environmental processes.

The long term record indicates that increases in surface UV irradiance in the Arctic occur mainly in late winter and early spring. A reason for this seasonal variation is considered to be the decline in springtime total ozone column, which was of about $5 \%$ per decade over the last twenty years. ${ }^{2}$ However future UV variability in polar regions is expected to be mainly due to changes in albedo and cloud cover changes in response to changes in the global climate system. ${ }^{3}$ Effects of changing UV radiation on the marine ecosystem have already been observed. ${ }^{4}$

Surface UV irradiance is significantly affected by clouds. ${ }^{5}$ Herman et al. ${ }^{6}$ analysed satellite measurements of the Earth's $380 \mathrm{~nm}$ reflectivity that combine the effects of surface reflectivity, aerosols, haze, cloud optical thickness, and the fraction of the scene covered by clouds. They reported that time series analysis

${ }^{a}$ Physikalisch-Meteorologisches Observatorium Davos, World Radiation Center, 7260, Davos Dorf, Switzerland

${ }^{b}$ Sektion für Biomedizinische Physik, Medizinische Universität Innsbruck, Austria

'Alfred-Wegener Institut für Polar und Meeresforschung, 27570, Bremerhaven, Germany

"National Research Council (CNR), Istituto di Acustica "O.M. Corbino", 00133, Roma, Italy

${ }^{e}$ National Research Council (CNR), Institute of Atmospheric Sciences and Climate (ISAC), 40129, Bologna, Italy

${ }^{f}$ Norwegian Institute for Air Research (NILU), 9296, Tromsø, Norway $\dagger$ Electronic supplementary information (ESI) available. See DOI: $10.1039 / \mathrm{b} 9 \mathrm{pp} 00170 \mathrm{k}$ over the period from 1979 to 1992 showed a trend of reflectivity of about $+3 \%$ per decade between $60^{\circ} \mathrm{N}$ and $70^{\circ} \mathrm{N}$. Such results indicate a systematic change of the environmental conditions at high latitude sites. A reliable long-time ground-based data set will provide useful information for understanding the relationship between UV irradiance variations and environmental changes in the Arctic.

\section{Instruments and methods}

In order to monitor surface UV irradiance, high quality instrumentation is needed. The requirements of data quality are provided, for example, by the World Meteorological Organisation (WMO). ${ }^{7}$ The Network for the Detection of Atmospheric Composition Change (NDACC) has specified very similar requirements for UV spectroradiometers, which are used to monitor spectral solar UV irradiance with the aim of trend detection. ${ }^{8} \mathrm{Ny}$-Ålesund hosts a primary NDACC station and the Alfred-Wegener Institut (AWI) has committed itself to provide data with the required quality to the NDACC and thus to the scientific community. A requirement to comply with the standards of the NDACC is a successful intercomparison with internationally recognized UV spectroradiometers, preferably with an NDACC instrument.

To achieve international comparability of the UV irradiance measured at Ny-Ålesund, a field intercomparison of UV spectroradiometers was organised at Ny-Ålesund in May and June 2009. The purpose of the campaign was the intercomparison of global solar irradiance measurements from two spectroradiometers and two filter radiometers participating in the Quality Assurance in the Arctic (QAARC)-Campaign (ARCFAC-026129-2008-44) with the travel reference spectroradiometer QASUME. This reference spectroradiometer is operated by the European UV Calibration Center (EUVC) of the World Radiation Center at Davos, which was designated Global Atmosphere Watch (GAW) regional UV calibration center for the European region (WMO RA VI (Europe)) in January 2008. 
The two spectroradiometers were operated by the AlfredWegener Institut, Germany, and the Istituto di Acustica "O.M. Corbino" of the National Research Council (CNR), Italy, respectively, which perform continuous measurements of spectral solar irradiance at $\mathrm{Ny}-\mathrm{A} l e s u n d$. One filter radiometer was operated by the Institute of Atmospheric Sciences and Climate (ISAC) of the CNR in Bologna, Italy, and the second by the Norwegian Institute for Air Research (NILU), Norway. The specifications of each instrument can be found in the respective sections below.

The intercomparison site was located on the measurement platform of the Sverdrup Research Station, at the Norsk Polarinstitutt (NPI) at $\mathrm{Ny}-\AA ̊$ Alesund; latitude $78.92^{\circ} \mathrm{N}$, longitude $11.93^{\circ} \mathrm{E}$ and altitude $45 \mathrm{~m}$ above sea level. The horizon of the measurement site is unobstructed down to $5^{\circ}$ above the horizon.

While QASUME, AWI and the two multifilter radiometers were located on the same measurement platform within $10 \mathrm{~m}$ from each other, the UV spectroradiometer, Brewer \#050, operated by CNR was located at a distance of about $50 \mathrm{~m}$ on the roof of an adjacent building. The relative large displacement of this instrument with respect to the other instruments led to some additional variability between it and the QASUME reference in case of rapidly varying weather conditions.

The measurement campaign lasted 11 days, from the morning of May 27 to the afternoon of June 6, 2009. The measurement protocol was to measure one solar irradiance spectrum from 290 to $450 \mathrm{~nm}$, every $0.5 \mathrm{~nm}$, and $1.5 \mathrm{~s}$ between each wavelength increment. The scans were performed every $30 \mathrm{~min}$ all day round (24 h).

\subsection{The transportable QASUME reference spectroradiometer}

The travelling reference spectroradiometer consists of a commercially available Bentham DM-150 double monochromator with an effective focal length of $300 \mathrm{~mm}$ and two gratings of 2400 lines per mm. The wavelength range is 250 to $500 \mathrm{~nm}$ and the entrance and exit slit width was chosen to yield a near triangular slit function with a full width at half maximum resolution of about $0.8 \mathrm{~nm}$. The solar irradiance is sampled through a specially designed entrance optic (CMS-Schreder Model UV-J1002) which is connected to one port of the spectroradiometer through a quartz fiber. The second entrance port holds a pencil ray mercury lamp (Oriel Model 6035) which is used to check the wavelength setting of the spectroradiometer. An end-window-type bialkali photomultiplier (PMT, Electron tubes 9250QB) is used as detector and is operated in current mode. Since the instrument is designed for outdoor solar measurements, the whole spectroradiometer system including the data acquisition electronics are contained in a temperature-controlled weatherproof box which is stabilised to a predetermined temperature with a precision of $0.1 \mathrm{~K}$. As the QASUME spectroradiometer was designed to measure at locations far from its laboratory, a portable irradiance scale was devised. It is composed of a portable lamp enclosure, a set of $250 \mathrm{~W}$ tungsten halogen lamps and a computer controlled feedback system. The portable irradiance scale was validated in June 2004 by measurements of the primary irradiance standard of the Physikalisch-Technische Bundesanstalt in Braunschweig, Germany (PTB). The instrument has been in routine use for on-site quality assurance of spectral solar irradiance measurements since
2002 and has become the reference instrument for spectral solar UV measurements in Europe. ${ }^{9}$ A comprehensive uncertainty budget was established for global irradiance measurements obtained with the QASUME reference spectroradiometer. At wavelengths longer than $310 \mathrm{~nm}$, the expanded uncertainty (coverage factor $k=$ 2 ) is of the order of $5 \%$ and increases towards shorter wavelengths; at $300 \mathrm{~nm}$, the uncertainty is estimated to be $9 \%$ essentially due to the lower signal to noise ratio in this wavelength range. ${ }^{10}$

The QASUME spectroradiometer has been performing site visits to European UV monitoring stations since 2002. Between 2002 and 2008 more than 30 stations were visited and several of them were visited multiple times within this period. ${ }^{9}$ The audit reports are publicly available through the project website (http://www.pmodwrc.ch/euvc/euvc.html), thus providing an objective quality assessment of the solar UV measurements performed at these sites to the scientific community. The aim of the EUVC is to provide a stable UV irradiance reference traceable to the international system of units (SI) through the operation and maintenance of radiation reference standards at the EUVC. ${ }^{11}$

The QASUME spectroradiometer was calibrated several times during the intercomparison using two portable small power lamps. The daily mean responsivity varied by less than $\pm 1 \%$. The diffuser entrance optic was heated to a temperature of $28^{\circ} \mathrm{C}$, which varied by less than $\pm 1{ }^{\circ} \mathrm{C}$ during the intercomparison period. The spectral wavelength shifts of the measured solar spectra were evaluated using the SHICRivm algorithm ${ }^{12}$ and varied by less than $\pm 0.03 \mathrm{~nm}$ (5 to $95 \%$ percentile).

\subsection{The UV spectroradiometer of AWI}

The new AWI UV spectroradiometer was installed at Ny-Ålesund in March 2009 in order to perform long-term measurements complying with the data requirements of the NDACC. The entrance optic of the new AWI UV spectroradiometer consists of a shaped Teflon diffuser, which is protected by a quartz dome (CMS-Schreder Model UV-J1002) and which contains an internal temperature sensor. The radiation is guided into the entrance slit of the monochromator through an optical fiber. The central element of the spectroradiometer is a model DMc150 double monochromator from Bentham Instruments, Ltd., with an effective focal length of $300 \mathrm{~mm}$. The double monochromator consists of two identical single Czerny-Turner monochromators. The entrance and exit slits have a fixed width of $0.56 \mathrm{~mm}$. The middle slit is set to $1.48 \mathrm{~mm}$. Holographic reflection gratings with 2400 grooves per $\mathrm{mm}$ are employed in each monochromator. A bialkali end window PMT is used as a detector. The output current of the PMT is processed by a decadal current amplifier. This signal is converted to a digital signal, which can be further processed by a computer. To operate the spectroradiometer in a stable manner, it is placed inside a temperature-controlled weatherproof box. During the intercomparison campaign the temperature inside this weatherproof box was between 19.5 and $21^{\circ} \mathrm{C}$. The temperature of the entrance optics ranged from $7{ }^{\circ} \mathrm{C}$ to $27^{\circ} \mathrm{C}$ during the campaign. Therefore a temperature correction based on the published temperature dependence of this particular CMS-Schreder Model was applied. ${ }^{13}$ The temperature correction varied by $\pm 1.5 \%$ with an average correction of $-2 \%$. The relative humidity inside the box is also monitored and reached 22 to $30 \%$. 
The spectroradiometer is calibrated with a portable $150 \mathrm{~W}$ lamp system, which is in turn calibrated relative to two $1000 \mathrm{~W}$ standard lamps obtained from an accredited laboratory. During the campaign the spectral responsivity, based on three calibrations performed at the beginning, middle and end of the intercomparison, varied by $\pm 1.0 \%$. The irradiance was calculated using the average spectral responsivity of the three calibrations taking into account the temperature of the input optics.

\subsection{The Brewer \#050 spectrophotometer from CNR-Roma}

The Brewer spectrophotometer was installed at $\mathrm{Ny}$-Ålesund in May 1997 to measure UV radiation, total column ozone, sulfur dioxide and nitrogen, as well as the vertical profile of ozone. Ground-based observations are carried out directly from solar and lunar radiation or by diffuse zenith sky radiation. Since May 2009 the instrument has been in continuous operation during the whole year. It operates in unattended mode, managed by remote internet connection, while regular maintenance (instrument cleaning) is provided by on-site personnel. An in-depth maintenance is performed twice a year by CNR personnel and periodically the Brewer is calibrated by an external company. The last calibration was performed by Ken Lamb, International Ozone Services, Inc. (IOS), during May 4-11, 2009. The UV calibration was determined with IOS $50 \mathrm{~W}$ lamps 201, 202, 203 using QL (quick lamp scan) routine and the responsivity file UVR12509.104 was calculated using the "Lampspro" program. Two of the five local $50 \mathrm{~W}$ lamps were measured in addition and their results compared very well to QL scans from 2006. Thus the instrument has remained very stable. During the intercomparison campaign the command "UA" (timed UX scan) was used to perform half-hour synchronised scans between 290 and $363 \mathrm{~nm}$ with a step-size of $0.5 \mathrm{~nm}$.

\subsection{The multifilter radiometer UV-RAD from ISAC, CNR}

The narrow-band filter radiometer UV-RAD has been designed at the Institute of Atmospheric Sciences and Climate of the Italian National Research Council to measure the solar UV irradiance at seven channels picked at 300, 306, 310, 314, 325, 338 and $364 \mathrm{~nm}$ wavelengths. Each channel contains an interference filter and several passband components which define altogether the corresponding spectral characteristics presenting transmittance between $12 \%$ and $27 \%$ for different channels and the full width at half maximum (FWHM) varying from 0.7 to $1 \mathrm{~nm}$. The UVRAD is able to perform an overall scan of the channels within a time interval of about $90 \mathrm{~s}$, recording the data and operating autonomously.

The measurements, performed by the UV-RAD allow the retrieval of the total ozone amount applying the method developed by Stamnes et al. ${ }^{14}$ The spectral features of solar UV irradiance at the ground can be reconstructed fitting the spectrum evaluated through a radiative transfer model at the time of observation using the recovered total ozone as an input, to the nearly monochromatic measurements performed by UV-RAD.${ }^{15}$ Finally, the retrieved spectrum is used to assess the UV index applying the equation defining this parameter. ${ }^{16}$ During the QAARC campaign, the $300 \mathrm{~nm}$ channel of the instrument based at $\mathrm{Ny}$-Ålesund showed an appreciable discrepancy with respect to the QASUME spectroradiometer. That is why this wavelength has been removed from the procedure which estimates the UV index until the problem is resolved.

\subsection{The multifilter radiometer GUV 9275 from NILU}

The GUV instrument is manufactured by Biospherical Instruments Inc. It is a robust, weatherproof, temperature-stabilized instrument (usually at $40{ }^{\circ} \mathrm{C}$ ). The optics consist of a Teflon diffuser followed by interference filters and UV-sensitive photodetectors. It has five channels in the UV with nominal center wavelengths at 305, 313, 320, 340 and $380 \mathrm{~nm}$. The FWHM of each channel is approximately $10 \mathrm{~nm}$. The instrument is computer controlled and 1 minute average data from each channel is logged continuously together with the instrument temperature.

The GUV multi-channel radiometer 9275 was originally part of the Norwegian UV-monitoring Network, a cooperative program run by The Norwegian Radiation Protection Authorities (NRPA) and NILU. The GUV at Ny-Ålesund was left out of the program due to lack of funding for running the program, but calibration and maintenance has been kept at the same high level. Calibration against the network's travelling standard is usually performed once a year, preferably in May or June when the solar zenith angle (SZA) is relatively small and the chance for clear sky conditions is best. The raw data from the GUV is scaled with a scaling factor to meet the level of the travelling standard before the data is applied in any analyses. The travelling standard is calibrated against a relative radiation source before and after shipment to $\mathrm{Ny}$-Ålesund in order to trace eventual drift of the instrument due to the shipment. The calibration used here was performed in June 2009; the calibrations show a slight drift in sensitivity of about $-1 \%$ per year as judged from the calibrations performed in 2007 and 2008.

Change in channel sensitivity in this kind of radiometer is a commonly known problem and the long-term changes (over more than a decade) may reach more than $20 \%,{ }^{17}$ which makes regular calibrations extremely important. In turn, the travelling standard is calibrated on a regular basis against a reference spectroradiometer to ensure best possible traceability of the network instruments. The travelling standard changes less than the network instruments ( $-2 \%$ to $+5 \%$ in the period 1995 to 2001 ), probably due to much lower exposure. ${ }^{17}$ All calibration routines are described in detail in ref. 17. Primary and secondary radiation standards are both traceable to NIST. The main data product from the instrument is the CIE erythemal UV dose (or UV index), but also total ozone column, cloud optical depth, and cloud transmission are available products. The method of retrieving the UV dose from the data is based on assimilating the radiometer data with either accurately measured high-resolution spectrometer data or radiative transfer modelling data for different atmospheric conditions with respect to ozone and SZA. This is done by solving a set of equations using raw data from 4 of the GUV channels $(305,320,340$, and $380 \mathrm{~nm})$ at 4 different atmospheric conditions, with respect to total ozone column and SZA. The method is described in detail by Dahlback. ${ }^{18}$

\section{Results}

In total, 358 and 447 synchronised simultaneous solar spectra are available from the AWI and CNR spectroradiometers respectively. For the multifilter radiometers from ISAC and NILU, their UV index product was evaluated with respect to the UV index values 
retrieved from the measured solar spectra of the QASUME spectroradiometer. The reference time of the solar spectrum measured by the QASUME spectroradiometer was obtained from the mean of the individual times at each wavelength of a scan, weighted with the erythemally weighted irradiance at each wavelength. ${ }^{19}$

The UV indices determined by all instruments are shown in Fig. 1. As can be seen in the figure, measurements of solar irradiance were possible $24 \mathrm{~h}$ a day due to the high latitude of $\mathrm{Ny}$ Allesund. Indeed, the minimum solar zenith angle (SZA) varied from $57.5^{\circ}$ on May 28 to $56.2^{\circ}$ on June 6,2009 . The maximum SZA varied accordingly from $79.5^{\circ}$ on May 28 and to $78.2^{\circ}$ on June 6 . The weather conditions during the campaign varied between fully overcast skies to clear sky days, including occasional snow fall. The best conditions for an intercomparison are either clear or fully overcast skies; in the first case, the measurements show the highest diurnal variability and instrument characteristics such as angular response errors are clearly visible; in the second case, global irradiance measurements consist only of diffuse irradiance with a correspondingly different behavior with respect to the clear sky case. During the campaign, a clear sky period occurred from June 2 (day of year 153 in Fig. 1) to June 4 (155), and fully overcast days occurred on May 28 (148), May 30 (150), June 5 (156) and June 6 (157). The remaining days were a mix between overcast skies with no direct solar irradiance and clear sky periods with clouds not obscuring the solar disk.

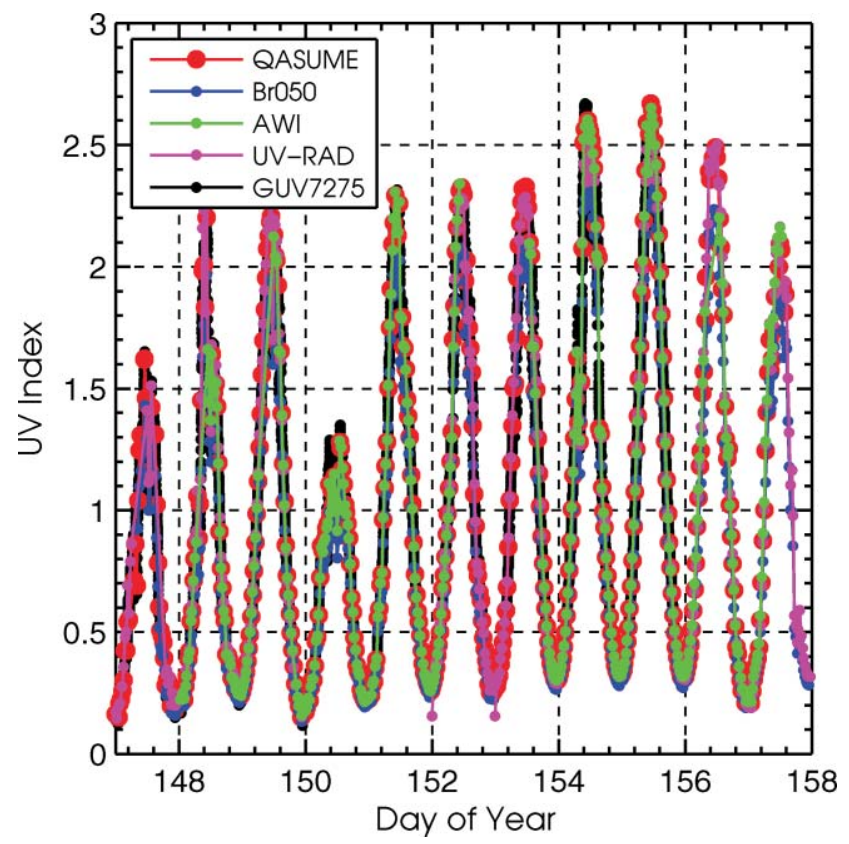

Fig. 1 Solar UV index measurements from the AWI spectroradiometer, Brewer \#050, the multifilter radiometer UV-RAD, the multifilter radiometer GUV7275 and the QASUME reference spectroradiometer. The measurement period lasted from 27 May to 6 June 2009 and the location was Ny-Ålesund, Svalbard, Norway.

The intercomparison of the spectroradiometers from AWI and CNR with the QASUME spectroradiometer followed a prescribed formal protocol: ${ }^{10}$ as a first step, each measured spectrum was wavelength-corrected with respect to an extraterrestrial spectrum and convolved to a nominal $1 \mathrm{~nm}$ resolution using the SHICRivm algorithm. ${ }^{12}$ Thus, the comparison between the spectroradiome- ters was performed with solar spectra based on a common wavelength scale and a common resolution of $1 \mathrm{~nm}$. This procedure helps to considerably reduce variabilities introduced by wavelength misalignments or differences in instrumental resolution, which would introduce substantial spectral variabilities due to the Fraunhofer structure of the solar spectrum, and has been in routine use in all major spectroradiometer intercomparisons since 1997. ${ }^{20}$

All spectra were individually compared to those measured simultaneously with the QASUME spectroradiometer for the whole duration of the campaign. The relative stability of the instruments was determined using $5 \mathrm{~nm}$ wide wavelength bands of the spectral ratios, centered at 305, 310, 320, 350 and either $358 \mathrm{~nm}$ for Brewer \#050 or $395 \mathrm{~nm}$ in the case of the AWI spectroradiometer. A detailed report of the intercomparison containing additional figures and results is available on the EUVC web-site at http://www.pmodwrc.ch/euvc/qasume_audit/reports/2009_ 06_norway_nyalesund.pdf.

\subsection{The AWI spectroradiometer}

The temporal variation of the spectral ratios between AWI and QASUME is shown in Fig. 2 for the period 28 May to noon of June 6, 2009. Measurements of AWI from noon of June 1 to noon of June 2 are missing due to an error in the controlling software of the spectroradiometer. Otherwise only a very few individual spectra are missing due to the field calibration of the AWI spectroradiometer during the campaign.

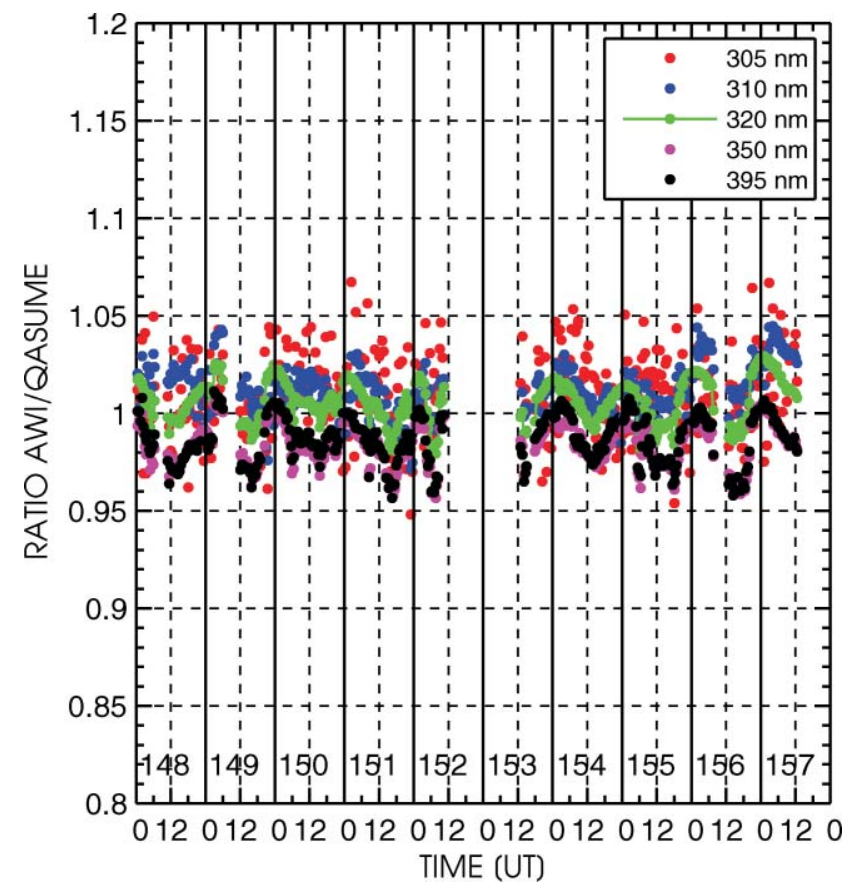

Fig. 2 Temporal variation of the spectral ratios at $5 \mathrm{~nm}$ wide wavelength bands centered at 305, 310, 320, 350, and $395 \mathrm{~nm}$ between the AWI spectroradiometer and the QASUME reference spectroradiometer. The measurement frequency was one spectrum every $30 \mathrm{~min}$. The data gap between the afternoon of June 1 (152) and morning of June 2 (153) is due to missing measurements of the AWI spectroradiometer because of a software error. The longest continuous clear sky period occurred from June 2 to 4 (day of year 153 to 155 ). 
The average spectral ratio between AWI and QASUME shown in Fig. 3 was obtained from a total of 358 individual solar spectra. The 5th and 95th percentiles are also shown and illustrate the excellent stability of both instruments during the whole campaign. The gray shaded area in the figure marks the minimum and maximum deviations of all spectral ratios and thus demonstrates that there was not one single out-lier measurement over the course of the 10 day campaign with spectra measured every $30 \mathrm{~min}$. This result is particularly satisfying for an instrument such as AWI, whose purpose is to continuously monitor the solar UV irradiance in a remote site with harsh environmental conditions. The average spectral ratio between AWI and QASUME shows a slight spectral variation of $\pm 3 \%$ between 300 and $400 \mathrm{~nm}$ with an overall offset of $1 \%$. Thus the absolute irradiance measured with AWI is well within the stated uncertainties of both instruments. The variability of the ratios over the 10 day comparison as shown in Fig. 2 is $\pm 3 \%$.

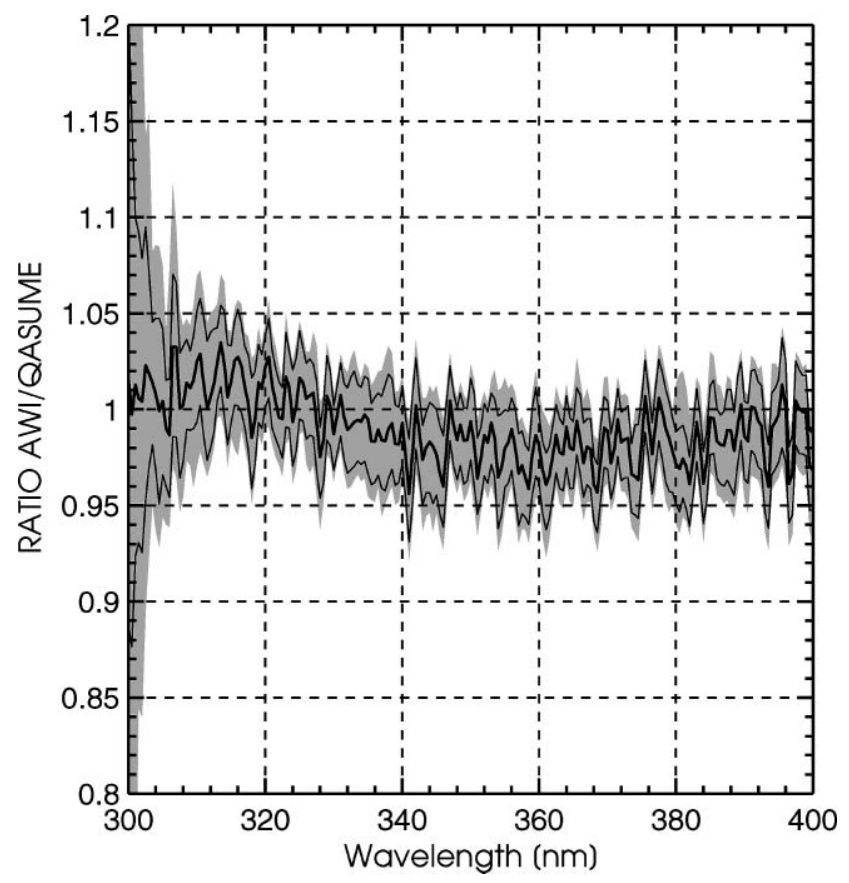

Fig. 3 Thick line: Average spectral ratio of 358 simultaneously measured solar spectra between the AWI spectroradiometer and the QASUME reference spectroradiometer. The two thin lines represent the 5th and 95th percentiles of all the spectra. The gray shaded area shows the maximal and minimal deviations seen between the two instruments during the intercomparison.

The spectral wavelength shifts (i.e. the difference between the measured and the assigned wavelength) of AWI were obtained by a comparison to an extraterrestrial spectrum using the SHICRivm algorithm and are shown in Fig. 4. Thus, the wavelength stability was between \pm 0.01 and $\pm 0.02 \mathrm{~nm}$, depending on the chosen wavelength interval. The spectral wavelength shifts varied between $-0.05 \mathrm{~nm}$ at $340 \mathrm{~nm}$ and $+0.06 \mathrm{~nm}$ at $390 \mathrm{~nm}$ with an average deviation of $+0.01 \mathrm{~nm}$. The wavelength shifts in the UV-B range, where the influence on the solar spectrum would be the most pronounced due to the sharp spectral gradient in intensity, are below $\pm 0.02 \mathrm{~nm}$ and thus have a negligible influence on the measurements.

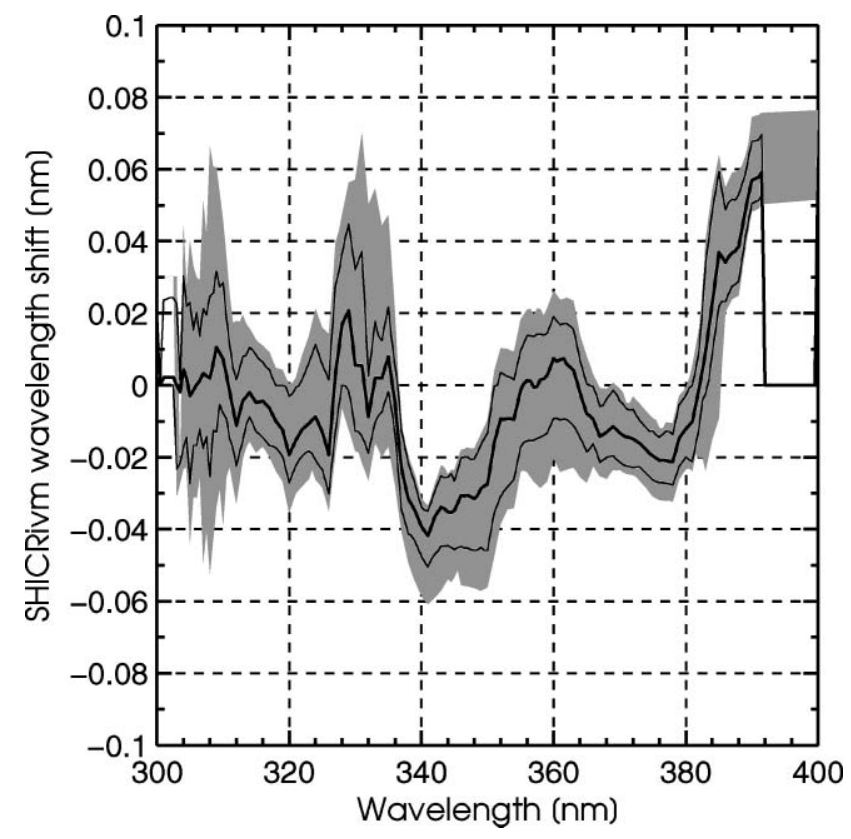

Fig. 4 The full range of spectral wavelength shifts of the AWI spectroradiometer as calculated by the SHICRivm algorithm ${ }^{12}$ is shown by the gray shaded area. The thick black line represents the average and the thin lines are the 5 th and 95 th percentiles.

\subsection{The Brewer \#050 spectrophotometer}

The temporal variation of the spectral ratios between Brewer \#050 and QASUME is shown in Fig. 5 for the period 27 May to noon of June 6, 2009. Due to the limited wavelength range of Brewer \#050, which extends only to $363 \mathrm{~nm}$, the longest common wavelength band was centered at $358 \mathrm{~nm}$ for the analysis. The average spectral ratio between Brewer \#50 and QASUME is shown in Fig. 6 and was obtained from a total of 447 individual solar spectra.

The 5th and 95th percentiles shown in this figure also demonstrate the very good stability of Brewer \#050 during the whole campaign. The gray shaded area shows some larger spectral deviations which are for the most part due to changing weather conditions during several solar spectra which affected Brewer \#050 and QASUME at slightly different times in the scan due to their physical separation of about $50 \mathrm{~m}$. A pronounced drop in the ratios in the morning of May 28 is due to snow accumulating on the dome of Brewer \#50 while the heated domes of the AWI and QASUME spectroradiometers remained free of snow. The instrument was cleaned at 9 UT after which the ratios between Brewer \#050 and QASUME returned to their average values.

The figures show that, on average, Brewer \#050 measures about 10 to $15 \%$ less than QASUME, depending on the weather conditions. This under-estimation of global irradiance is a common feature of standard Brewer spectrophotometers using a flat Teflon diffuser as input optic, with a correspondingly large angular response error. ${ }^{21,22}$ Indeed, during clear days, the ratios at longer wavelengths show a pronounced decrease which is correlated to increasing SZA (see Fig. 7) with a minimum around $70^{\circ}$ SZA. In contrast, this wavelength dependency is absent during overcast days with only diffuse irradiance. Assuming that the irradiance references of Brewer \#050 and QASUME are within 


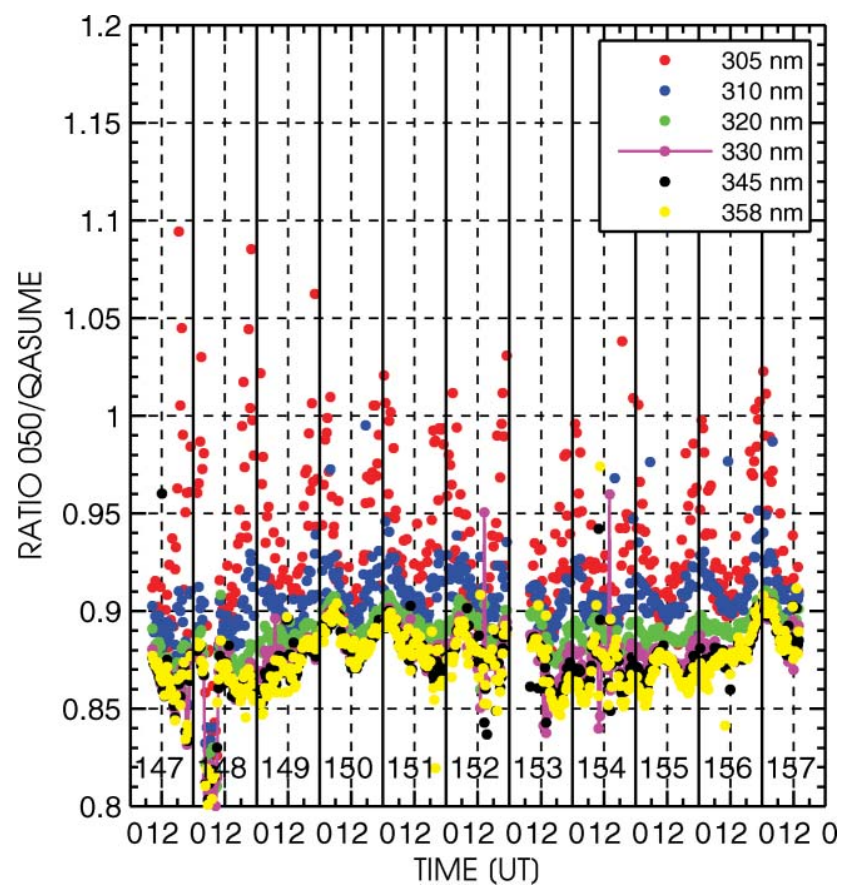

Fig. 5 Temporal variation of the spectral ratios at $5 \mathrm{~nm}$ wide wavelength bands centered at $305,310,320,330,345$, and $358 \mathrm{~nm}$ between Brewer \#050 and the QASUME reference spectroradiometer. The low values in the morning of May 28 (148) are due to snow on the dome of Brewer $\# 050$ which was cleaned at 9 UT. The longest continuous clear sky period occurred from June 2 to 4 (day of year 153 to 155).

$\pm 3 \%$ (Ken Lamb, personal communication), most of the observed differences between Brewer \#050 and QASUME can be attributed to a diffuse cosine error of about 0.91 , which is a reasonable value for Brewer spectrophotometers.

The average spectral ratio shown in Fig. 6 increases significantly below $310 \mathrm{~nm}$. Similarly, the wavelength bands centered at 305 and $310 \mathrm{~nm}$ show an over-estimation of the global irradiance correlated to the SZA. Both features are the consequence of the stray light in the Brewer \#050 single monochromator, which is not able to sufficiently discriminate radiation from longer wavelengths in the UV-B wavelength region.

The spectral wavelength shifts of Brewer \#050 are shown in Fig. 8. The instrument has a remarkable wavelength stability of $\pm 0.01 \mathrm{~nm}$ over the whole wavelength range. The spectral wavelength shifts vary between $-0.01 \mathrm{~nm}$ and $+0.04 \mathrm{~nm}$ with an average deviation of $+0.015 \mathrm{~nm}$. The wavelength shifts in the UV-B range, where the influence on the solar spectrum would be the most pronounced due to the sharp spectral gradient, are below $\pm 0.02 \mathrm{~nm}$ and thus have a negligible influence on the measurements.

\subsection{The UV-RAD multifilter radiometer}

The UV-RAD radiometer had hardware problems before the campaign (water intrusion in the entrance optics) and required maintenance. For the following intercomparison the UV-RAD radiometer was therefore uncalibrated and used initial measurements from QASUME to retrieve its instrumental calibration constants. The period of May 26 to May 31 was used to calibrate UV-RAD based on the QASUME measurements. The remaining intercomparison period, June 1 to 6 , was used to assess

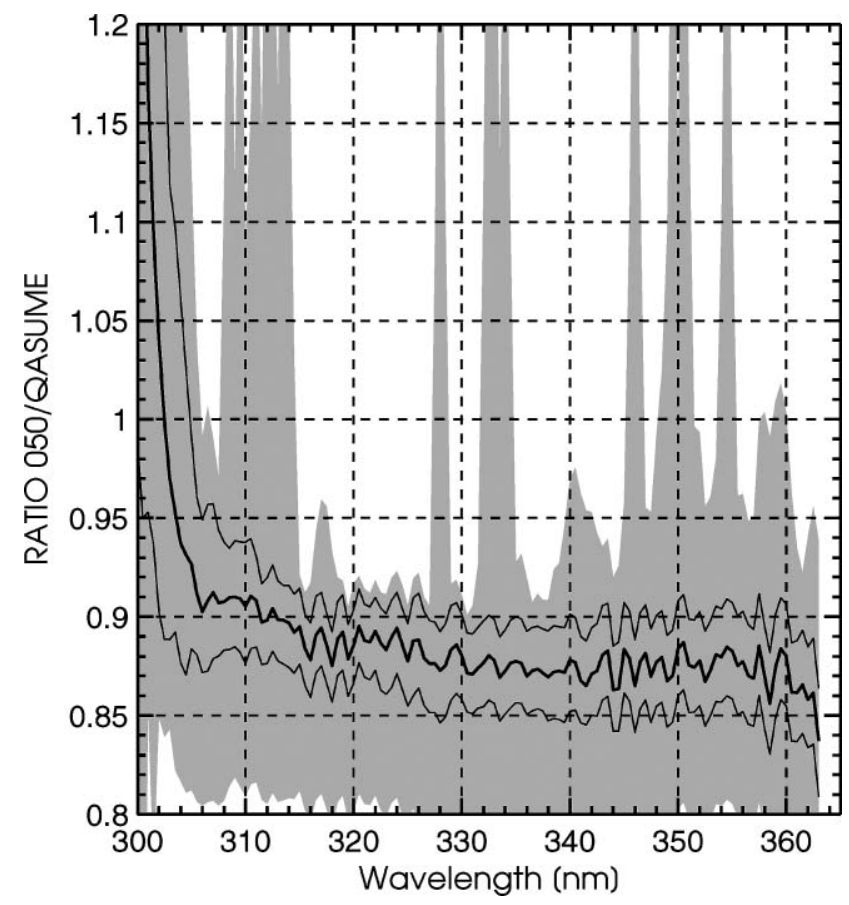

Fig. 6 Thick line: Average spectral ratio of 447 simultaneously measured solar spectra between Brewer \#050 and the QASUME reference spectroradiometer. The two thin lines represent the 5 th and 95 th percentiles of the spectra. The gray shaded area shows the maximal and minimal deviations seen between the two instruments during the intercomparison.

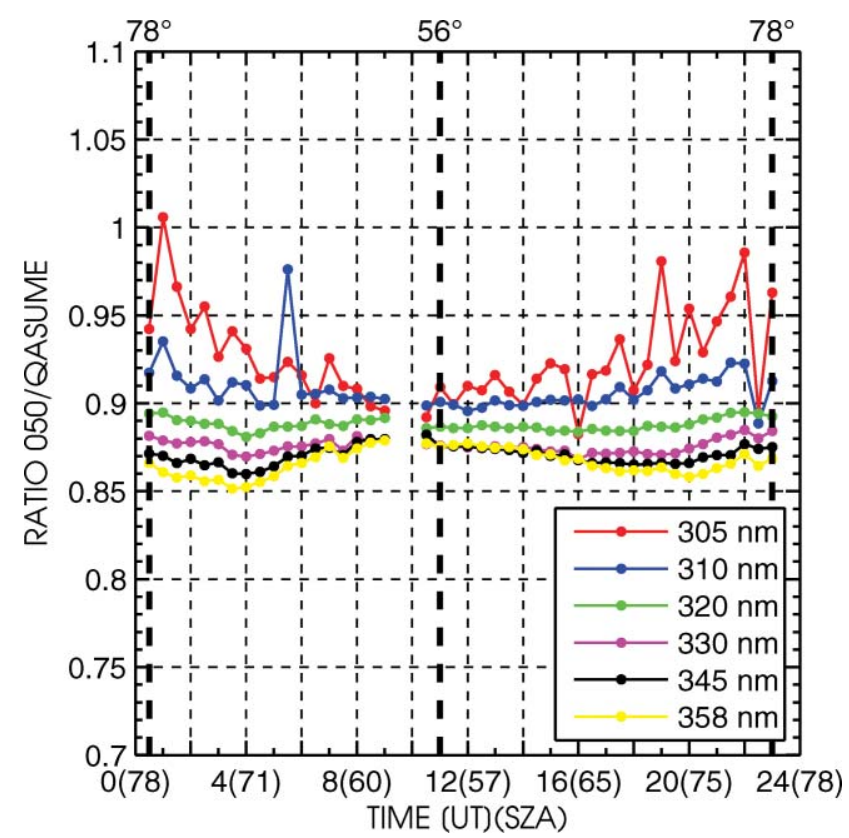

Fig. 7 Diurnal variation of the ratios between Brewer \#050 and the QASUME reference spectroradiometer on June 4, 2009. The weather conditions were clear with few cirrus clouds. The SZA is shown in parentheses beside the time of the day in the $x$-axis of the figure.

the radiometer. Fig. 1 shows the UV index as measured with the UV-RAD radiometer and the QASUME spectroradiometer. Measurements from UV-RAD were on average $1 \%$ lower than QASUME and varied by about $10 \%$ as shown in Fig. 9. The comparatively large variations of the ratio UV-RAD to QASUME 


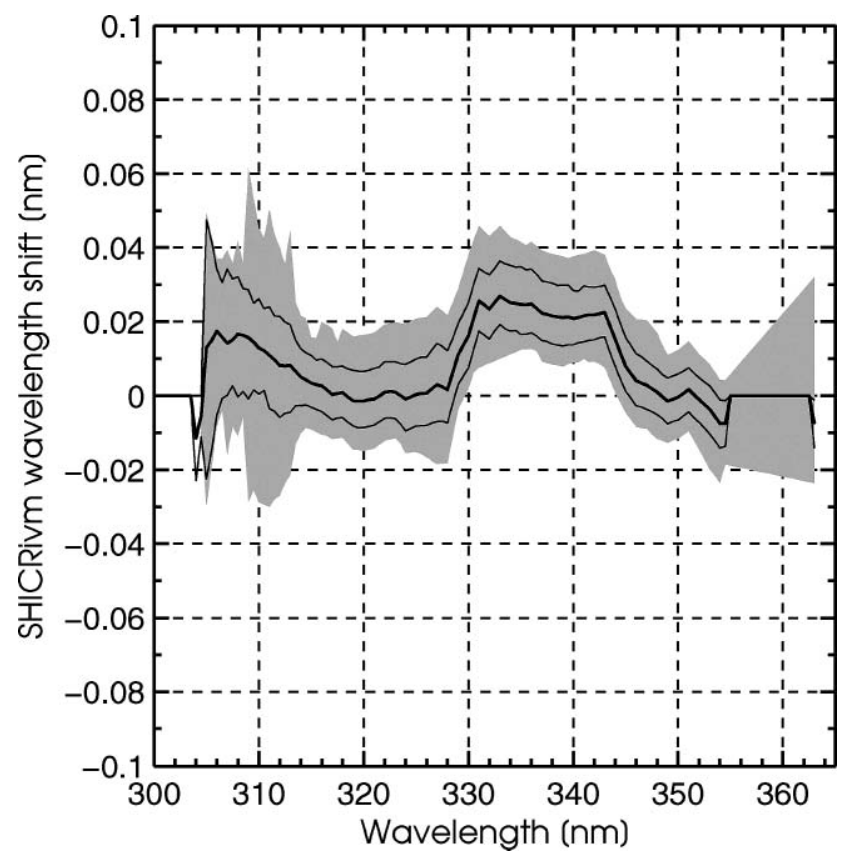

Fig. 8 The full range of spectral wavelength shifts of Brewer \#050 as calculated by the SHICRivm algorithm ${ }^{12}$ is shown by the gray shaded area. The thick black line represents the average and the thin lines are the 5th and 95th percentiles.

shown in the figure can be partly accounted by the differences in the measurement time schedules of both instruments during cloudy conditions, and also by the errors in the retrieved ozone amount used to reconstruct the solar UV spectrum at the ground due to the missing $300 \mathrm{~nm}$ UV-RAD channel, as was noted earlier.

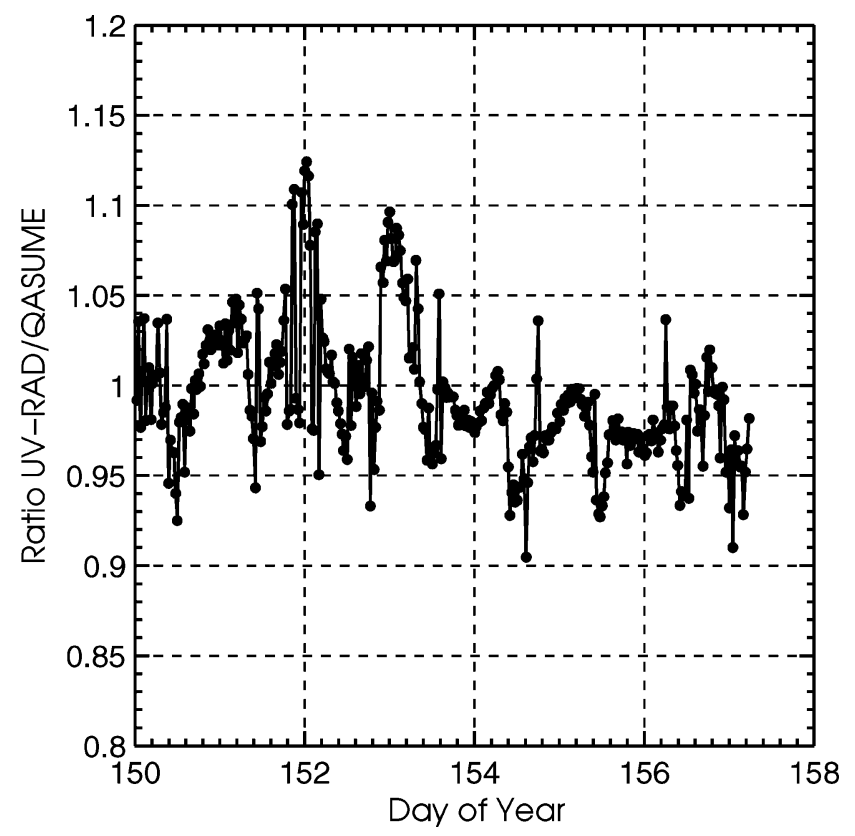

Fig. 9 Ratio between the UV indices determined by UV-RAD to the ones from the QASUME spectroradiometer.

\subsection{The GUV9275 multifilter radiometer}

The instrument provided one minute average values of UV index on a continuous basis for the whole duration of the campaign (see Fig. 1). Since originally the instrument was not meant to participate at this intercomparison, it operated in its usual network mode and the data was obtained only at the end of the campaign. Therefore its performance with respect to QASUME can be seen as a true site audit of a network instrument operating in its usual environment without special attention during the intercomparison phase.

The average ratio of the UV index measured by the GUV9275 and QASUME was 1.00 with a variability of $\pm 2.5 \%$, as shown in Fig. 10. The values of the GUV9275 were linearly interpolated to the times of the QASUME measurements. Due to the high temporal resolution of the GUV, the effect of this interpolation is negligible on clear sky days. For rapidly varying atmospheric conditions as found for example on 28 May, the different acquisition times are responsible for the observed short-term variations of about $4 \%$.

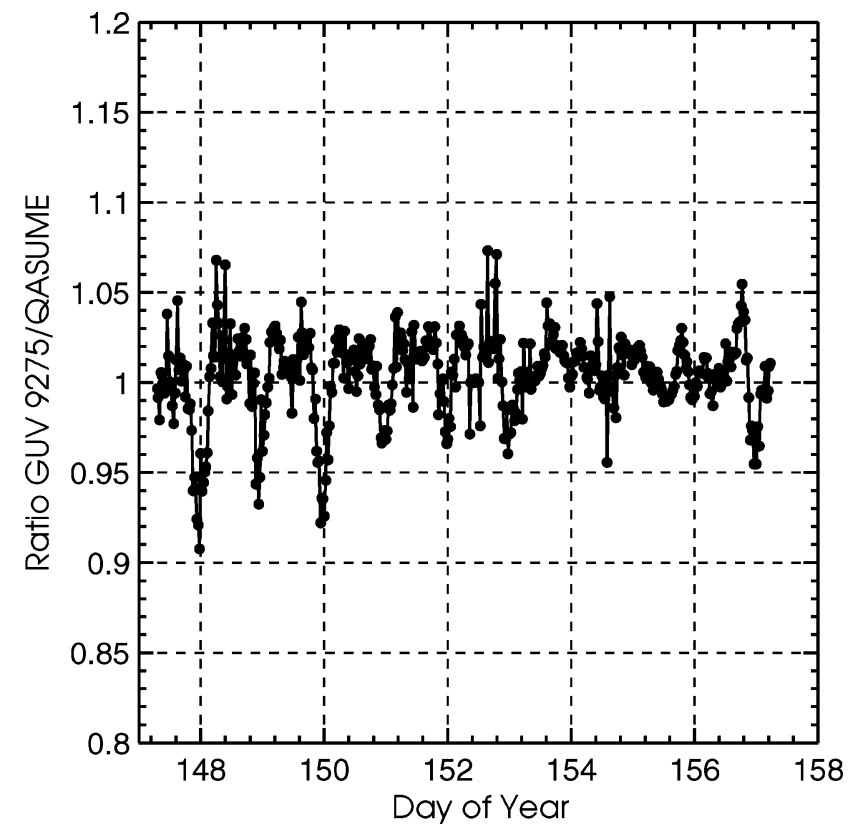

Fig. 10 Ratio between the UV indices determined by GUV9275 to the ones from the QASUME spectroradiometer. The UV indices of GUV9275 are available every minute and were linearly interpolated to the times of the QASUME measurements.

Around midnight, the erythemal dose rates were underestimated by up to $10 \%$ by the GUV, especially during the first days of the campaign where night-time values were the lowest of the campaign. This under-estimation occurs for UV indices below 0.3 and has therefore no practical relevance for any biological applications. Nevertheless, with regard to climatological investigations and for long-term trend detections this departure at low radiation levels is significant and needs to be resolved.

\section{Conclusions}

The investigation described here represents the first Arctic intercomparison of solar UV irradiance measurements between the 
transportable QASUME reference spectroradiometer and UV monitoring instruments operating continuously at Ny-Ålesund. This intercomparison provides a direct link, through the QASUME reference spectroradiometer, with UV measurements performed at other audited UV monitoring sites in Europe.

The results underline the importance of performing an independent assessment of UV monitoring instruments using a validated spectroradiometer: Two instruments provided stable and reliable UV measurements with less than 5\% differences to the QASUME spectroradiometer, while two other instruments provided measurements with greater differences to the reference. The differences observed with Brewer $\# 050$ are partly due to not accounting for imperfections in the global entrance optic, as well as a temperature dependence found in virtually all instruments of that type. The hardware problems of the UV-RAD radiometer precluded an independent verification of its performance during the intercomparison. Nevertheless, measurements from the intercomparison were used to calibrate the radiometer and to verify its stability during the intercomparison period. The observed variability of about $10 \%$ and sudden intensity jumps of the same magnitude remain to be explained.

This intercomparison should be seen as a first step towards the stated goal of providing a long-term data set of quality assured UV radiation data at $\mathrm{Ny}$-Ålesund, also within the NDACC. Indeed, NDACC protocols suggest site audits to be repeated at regular intervals to assess the continued quality of the UV measurements performed at Ny-Ålesund.

\section{Acknowledgements}

This intercomparison was partly funded by the ARCFAC project No 026129-2008-44. We thank the staff from the North Polar Institute for hosting the comparison on the measurement platform of Sverdrup Research Station. SW and OS also thank Moritz Sieber, station engineer at the AWIPEV research base at NyAllesund, for operating the AWI spectroradiometer during the intercomparison campaign and his support during the set-up of the instrument in March 2009.

\section{References}

1 M. Ikeda, R. Greve, T. Hara, Y. W. Watanabe, A. Ohmura, A. Ito and M. Kawamiya, Identifying Crucial Issues in Climate Science, EOS, Trans. Am. Geophys. Union, 2009, 90, 15.

2 B. Weatherhead, A. Tanskanen and A. Stevermer, Ozone and Ultraviolet Radiation, ACIA - Arctic Climate Impact Assessment, Cambridge University Press, 2005, Chapter 5, pp. 152-181.

3 A. F. Bais, D. Lubin, A. Arola, G. Bernhard, M. Blumthaler, N. Chubarova, C. Erlick, H. P. Gies, N. Krotkov, K. Lantz, B. Mayer, R. L. McKenzie, R. D. Piacentini, G. Seckmeyer, J. R. Slusser and C. S. Zerefos, Surface Ultraviolet Radiation: Past, Present, and Future, Scientific Assessment of Ozone Depletion: 2006, Global Ozone Research and Monitoring project - Report No. 50, World Meteorological Organization, 2007, Chapter 7, p. 572.

4 C. Wiencke, M. Y. Roleda, A. Gruber, M. N. Clayton and K. Bischof, Susceptibility of zoospores to UV radiation determines upper depth distribution limit of Arctic kelps: evidence through field experiments, J. Ecol., 2006, 94, 455-463.

5 J. Calbó, D. Pagès and J. A. González, Empirical studies of cloud effects on UV radiation: a review, Rev. Geophys., 2005, 43, RG2002.

$6 \mathrm{~J}$. R. Herman, D. Larko, E. Celarier and J. Ziemke, Changes in the Earth's UV reflectivity from the surface, clouds, and aerosols, J. Geophys. Res., 2001, 106, 5353-5368.

7 G. Seckmeyer, A. Bais, G. Bernhard, M. Blumthaler, P. Eriksen, R. L. McKenzie, C. Roy and M. Miyauchi, Instruments to measure solar ultraviolet radiation, part I: spectral instruments, WOM-GAW report, World Meteorological Organisation, Geneva, Switzerland, 2001, vol. 126, p. 30.

8 R. L. McKenzie, P. V. Johnston and G. Seckmeyer, UV spectroradiometry in the network for the detection of stratospheric change (NDSC), Solar Ultraviolet Radiation. Modelling, Measurements and Effects, ed. C. S. Zerefos and A. F. Bais, Springer Berlin, 1997, pp. 279-287.

9 J. Gröbner, M. Blumthaler, S. Kazadzis, A. Bais, A. Webb, J. Schreder, G. Seckmeyer and D. Rembges, Quality Assurance of spectral solar UV measurements: results from 25 UV monitoring sites in Europe, 2002 to 2004, Metrologia, 2006, 43, S66-S71.

10 J. Gröbner, J. Schreder, S. Kazadzis, A. F. Bais, M. Blumthaler, P. Görts, R. Tax, T. Koskela, G. Seckmeyer, A. R. Webb and D. Rembges, Traveling reference spectroradiometer for routine quality assurance of spectral solar ultraviolet irradiance measurements, Appl. Opt., 2005, 44, 5321-5331.

11 J. Gröbner and P. Sperfeld, Direct traceability of the portable QASUME irradiance scale to the primary irradiance standard of the PTB, Metrologia, 2005, 42, 134-139.

12 H. Slaper, H. A. J. Reinen, M. Blumthaler, M. Huber and F. Kuik, Comparing ground level spectrally resolved UV measurements using various instruments: A technique resolving effects of wavelength shift and slit width, Geophys. Res. Lett., 1995, 22, 2721-2724.

13 Lasse Ylianttila and Josef Schreder, Temperature effects of PTFE diffusers, Opt. Mater., 2005, 27, 1811-1814.

14 K. Stamnes, J. Slusser and M. Bowen, Derivation of total ozone abundance and cloud effects from spectral irradiance measurements, Appl. Opt., 1991, 30, 4418-4426.

15 B. Petkov, V. Vitale, C. Tomasi, U. Bonafè, S. S. Scaglione, D. Flori, R. Santaguida, M. Gausa, G. Hansen and T. Colombo, Narrow-band filter radiometer for ground-based measurements of global UV solar irradiance and total ozone, Appl. Opt., 2006, 45, 4383-4395.

16 Global Solar UV Index, WHO/SDE/OEH/02.2, World Health Organisation, 2002, p. 28.

17 B. J. Johnsen, O. Mikkelborg, M. Hannevik, L. T. Nilsen, G. Saxebøl and K. G. Blaasaas, The Norwegian UV monitoring program. Period 1995/96 to 2001, Strålevern Rapport 2002:4, Norwegian Radiation Protection Authority, Oslo, Norway, 2002, p. 40.

18 A. Dahlback, Measurements of biologically effective UV doses, total ozone abundances, and cloud effects with multichannel, moderate bandwidth filter instruments, Appl. Opt., 1996, 35, 6514-6521.

19 G. Hülsen and J. Gröbner, Characterisation and Calibration of UV Broadband Radiometers Measuring Erythemally Weighted Irradiance, Appl. Opt., 2007, 46, 5877-5886.

20 A. F. Bais, B. G. Gardiner, H. Slaper, M. Blumthaler, G. Bernhard, R. McKenzie, A. R. Webb, G. Seckmeyer, B. Kjeldstad, T. Koskela, P. J. Kirsch, J. Gröbner, J. B. Kerr, S. Kazadzis, K. Leszczynski, D. Wardle, W. Josefsson, C. Brogniez, D. Gillotay, H. Reinen, P. Weihs, T. Svenoe, P. Erikson, F. Kuik and A. Redondas, SUSPEN intercomparison of ultraviolet spectroradiometers, J. Geophys. Res., 2001, 106, 1250912525.

21 J. Gröbner, Improved entrance optic for global irradiance measurements with a Brewer spectrophotometer, Appl. Opt., 2003, 42, 35163521.

22 M. Anton, A. Serrano, M. L. Cancillo, J. M. Vilaplana, V. E. Cachorro and J. Gröbner, Correction of angular response error in Brewer UV irradiance measurements, J. Atmos. Oceanic Technol., 2008, 25, 20182027. 